\title{
Target controlled infu- sion of ketamine as \\ analgesia for TIVA with propofol
}

Cavin Gray FRCA,

Crispin F Swinhoe FRCA,

Ye Myint FRCA,

David Mason $\mathrm{PhD}$

Purpose: To determine the accuracy of a target controlled infusion system for ketamine and to assess its suitability for the provision of analgesia when used in conjunction with a propofol infusion in spontaneously breathing patients.

Methods: Nineteen, adult, ASA I-II patients scheduled for elective surgery were studied. After premedication with $20 \mathrm{mg}$ temazepam an appropriate plasma concentration of ketamine was selected and, when the target controlled infusion (TCl) system indicated that this had been achieved, anesthesia was induced and maintained using a propofol infusion. The plasma ketamine concentration was measured at predetermined intervals and cardiovascular and respiratory parameters recorded at 10 min intervals. Patients were reviewed in recovery and $24 \mathrm{hr}$ postoperatively to assess the adequacy of their recovery and the presence of any undesirable side effects.

Results: The TCl system had a median performance error against predicted plasma concentrations of $18.9 \%$ (SE $2.5 \%$ ) and a median absolute performance error of $23.3 \%$ (SE 2.3\%). Divergence was $20.3 \%$ (SE 30. I\%) and wobble was $12.9 \%$ (SE 2.1\%). There was a mean decrease in arterial pressure of $6.4 \%$ (SD | $9.7 \%$ ) and a mean increase in heart rate of $4.3 \%$ (SD 17.4\%). Little respiratory depression occurred and all patients made a rapid postoperative recovery with none describing unpleasant dreams or hallucinations.

Conclusion: The TCl system provided a clinically acceptable degree of control of the plasma ketamine concentration although some further improvement should be possible by amending the pharmacokinetic model. Clinically the combination with a propofol infusion proved to be a satisfactory anesthetic technique.

Objectif : Déterminer la justesse d'un système de perfusion cible contrôlée pour l'administration de kétamine et évaluer s'il convient à l'analgésie quand il est utilisé en conjonction avec une perfusion de propofol chez des patients dont la respiration est spontanée.

Méthode : Dix-neuf patients adultes, ASA I-II, admis pour une intervention chirurgicale élective ont participé à l'étude. Après l'administration d'une prémédication de $20 \mathrm{mg}$ de témazépam, on a sélectionné une concentration de kétamine plasmatique appropriée et, celle-ci étant atteinte selon les indications du système de perfusion cible contrôlée (PCC), on a induit et maintenu l'anesthésie avec une perfusion de propofol. La concentration plasmatique de kétamine a été mesurée à intervalles fixes et les paramètres cardiovasculaires et respiratoires à 10 min d'intervalle. Les patients ont été vus à la salle de réveil et $24 \mathrm{~h}$ après l'opération pour évaluer la qualité de la récupération et la présence de tout effet secondaire indésirable.

Résultats : Le système de PCC a présenté une erreur de performance médiane de 18,9\% (erreur type de 2,5 $\%$ ) concernant les concentrations plasmatiques prévues et une erreur de performance médiane absolue de 23,3 $\%$ (erreur type de 2,3\%). La divergence a été de $20,3 \%$ (erreur type de $30,1 \%$ ) et les fluctuations de $12,9 \%$ (erreur type de $2,1 \%$ ). Il y a eu une baisse moyenne de tension artérielle de $6,4 \%$ (erreur type de $19,7 \%$ ) et une baisse moyenne de la fréquence cardiaque de $4,3 \%$ (erreur type de 17,4\%). Une faible dépression respiratoire s'est produite et tous les patients ont connu une récupération postopératoire rapide sans rêves désagréables ou hallucinations.

Conclusion : Le système de PCC a fourni un degré de contrôle de la concentration plasmatique de kétamine acceptable en clinique quoique des améliorations ultérieures seront possibles en modifiant le modèle pharmacocinétique. La combinaison clinique avec une perfusion de propofol s'est révélée une technique anesthésique satisfaisante.

From the Department of Surgical and Anaesthetic Sciences, University of Sheffield, Royal Hallamshire Hospital, Sheffield, United Kingdom. Address correspondence to: Dr Cavin Gray, Department of Anaesthetics, Northern General Hospital, Herries Road, Sheffield, S5 7AU United Kingdom. Phone: 44-0114-243-4343; Fax: 44-0114-256-0394; E-mail: Cavin.Gray@Sheffield.ac.uk Accepted for publication July 11, 1999 
$\mathrm{T}$

HE intravenous anesthetic agent ketamine may be used in low doses to provide analgesia. ${ }^{1}$ It causes little respiratory depression $^{2}$ and may, therefore, be combined with propofol to provide analgesia in anesthetised spontaneously breathing patients, so preventing reflex movements without causing apnea. It causes rises in arterial pressure and pulse rate through sympathetic nervous system stimulation ${ }^{3}$ and therefore mitigates the hypotensive effects of propofol. ${ }^{4}$ Propofol has been shown to prevent the emergence phenomena that may occur following the use of ketamine. ${ }^{4}$

For all drugs administered intravenously, to achieve and maintain a stable plasma concentration, it is necessary to give a loading dose, followed by a continuous infusion. This infusion replaces drug removed from the plasma by distribution and elimination and, thus, its rate declines exponentially. To increase the plasma concentration during anesthesia a bolus will be required, followed by an altered infusion rate. Reductions in plasma concentrations may be achieved by stopping the infusion for an appropriate time and adjusting the subsequent infusion rate. The formulae for calculating supplementary loading doses and revised infusion rates are complex. Therefore, we have designed a target controlled infusion (TCI) system for ketamine. ${ }^{5}$ We programmed a palmtop computer with a weight-adjusted pharmacokinetic model for ketamine (Table I), ${ }^{6}$ and used it to control a Graseby 3400 infusion pump to achieve and maintain the desired plasma concentration.

The TCI system for ketamine aims to allow appropriate alterations in analgesia, where clinically indicated, to be achieved rapidly while reducing the wide swings in plasma concentrations which are likely with a manual infusion system.

The aim of this study was to evaluate the predictive performance of the ketamine TCI system by comparing computer predicted plasma concentrations with measured plasma concentrations and to assess the suitability of ketamine delivered by the TCI system for use with propofol during total intravenous anesthesia (TIVA) in spontaneously breathing patients.

\section{Methods}

The protocol was approved by the local Ethics Committee, and written informed consent was obtained from each patient. Nineteen patients (13 male) of ASA Grade 1 or 2, aged between 18 and 80 yr (mean $61 \mathrm{yr}$ ), within $20 \%$ of ideal body weight and scheduled for elective surgery for which a spontaneously breathing technique was appropriate were entered into the study. Surgical procedures performed included inguinal hernia repair, ligation and avulsion
TABLE I Pharmacokinetic parameters of ketamine used for computer model

\begin{tabular}{lll}
\hline & $($ mean \pm S.E.M. $)$ & \\
\hline $\mathrm{A}$ & $1.97 \pm 0.29$ & $\left(\mu \mathrm{g} \cdot \mathrm{ml}^{-1}\right)$ \\
$\alpha$ & $0.0632 \pm 0.01$ & $\left(\mathrm{~min}^{-1}\right)$ \\
$\mathrm{B}$ & $0.39 \pm 0.05$ & $\left(\mu \mathrm{g} \cdot \mathrm{m}^{-1}\right)$ \\
$\mathrm{B}$ & $0.004576 \pm 0.0008$ & $\left(\mathrm{~min}^{-1}\right)$ \\
$\mathrm{k}_{21}$ & $0.03296 \pm 0.003$ & $\left(\mathrm{~min}^{-1}\right)$ \\
$\mathrm{k}_{12}$ & $0.03296 \pm 0.005$ & $\left(\mathrm{~min}^{-1}\right)$ \\
$\mathrm{k}_{\mathrm{cl}}$ & $0.02023 \pm 0.004$ & $\left(\mathrm{~min}^{-1}\right)$ \\
$\mathrm{V}_{1}$ & $60.3 \pm 4.1$ & $(\mathrm{l})$ \\
$\mathrm{V}_{\mathrm{d} . \mathrm{ss}}$ & $203.5 \pm 21.6$ & $(\mathrm{l})$ \\
$\mathrm{f}_{\mathrm{c}}$ & $0.3 \pm 0.05$ & - \\
$\mathrm{V}_{\mathrm{d}, \mathrm{B}}$ & $214.3 \pm 35.2$ & $(\mathrm{l})$ \\
$\mathrm{Cl}_{\text {tot }}$ & $1226.8 \pm 285$ & $(\mathrm{ml} \cdot \mathrm{min})$ \\
\hline
\end{tabular}

Using linear open two compartment model $\mathrm{C}=\mathrm{Ae}^{-\mathrm{t}}+\mathrm{Be}^{-\mathrm{Bt}}$ and where $V_{s s}=$ volume of distribution at steady state, and $V_{d, B}$ at (phase; $f_{c}=$ fraction of dose in central compartment; $\mathrm{Cl}_{t o t}=$ total clearance.

of varicose veins, trans-urethral resection of the prostate and hemorrhoidectomy, the duration varying from 29 - $122 \mathrm{~min}$. Patients with arterial pressures greater than 160/100, ischemic heart disease, psychiatric disease, major abnormalities of liver function and patients for day case surgery were excluded.

Patients were premedicated with $20 \mathrm{mg}$ temazepam po one hour before surgery. After pre-oxygenation a predicted plasma ketamine concentration was selected and the infusion started. Previous studies had suggested that a plasma ketamine concentration of $200 \mathrm{ng} \cdot \mathrm{ml}^{-1}$ would be an appropriate initial target. ${ }^{1}$ Our initial experience with this system, however, suggested that this target concentration did not provide a satisfactory level of analgesia and subsequently an initial plasma ketamine concentration of $300 \mathrm{ng} \cdot \mathrm{ml}^{-1}$ was selected. As soon as the computer predicted that this concentration had been achieved a bolus of propofol was given at a rate of $600 \mathrm{ng} \cdot \mathrm{ml}^{-1}$ by infusion pump until a laryngeal mask airway could be inserted. A propofol infusion was then started at a rate of $10 \mathrm{mg} \cdot \mathrm{kg} \cdot \mathrm{hr}^{-1}$ for $10 \mathrm{~min}, 8$ $\mathrm{mg} \cdot \mathrm{kg} \cdot \mathrm{hr}^{-1}$ for $10 \mathrm{~min}$ and then maintained at 6 $\mathrm{mg} \cdot \mathrm{kg} \cdot \mathrm{hr}^{-1}$ thereafter, or adjusted according to clinical response. Patients breathed an air/oxygen mixture at an $\mathrm{FiO}_{2}$ sufficient to maintain an arterial oxygen saturation greater than $95 \%$. Following the start of the operative procedure the target concentration of ketamine was increased and decreased at least once to allow an assessment of the system's accuracy when such changes were made, and additionally adjusted if clinical responses indicated an inappropriate level of analgesia. The ketamine and propofol infusions were discontinued when clinically indicated. 
Plasma ketamine concentrations were measured using gas liquid chromatography ${ }^{7}$ from samples taken from a dedicated venous cannula as a baseline before starting the infusion and five minutes later; before an increase in target concentration, three and five minutes later; before a decrease in target concentration, on reaching it and five minutes later; prior to, five and ten minutes after discontinuing the infusion.

Patient monitoring comprised $\mathrm{FiO}_{2}, \mathrm{ECG}$, capnography, pulse oxymetry and non-invasive arterial pressure. Episodes of apnea of $>15 \mathrm{sec}$ and reflex patient movements were recorded as were pupil size and reaction at $10 \mathrm{~min}$ intervals during the procedure. The times of the patients first opening their eyes and of remembering their date of birth were recorded by recovery nurses who constantly observed the patients until awake and they were monitored in recovery and questioned the following day as to the occurrence of vivid dreams or hallucinations.

For each sample point the percentage performance error was calculated as

$$
P E(\%)=\frac{M-P}{P} \cdot 100
$$

where $M$ and $P$ are the measured and predicted concentrations. Performance error data were evaluated using the statistical methods suggested by Varvel et $a l^{8}$ The median performance error (MDPE) and median absolute performance error (MDAPE) were calculated for each patient and for each sampling time. The MDPE is a signed value which provides a measure of the direction of the performance error (bias) whereas the MDAPE disregards the sign of the error and is a measure of the precision of the system. Divergence, a measure of time-related changes in performance, and wobble, a measure of intrasubject variation in performance error were also calculated.

All four performance measures, MDPE, MDAPE, divergence and wobble were then calculated for the whole study population using a standard two stage approach. ${ }^{8}$

\section{Results}

In the population studied the MDPE was $18.9 \%$ (95\% confidence interval $14.0-23.8 \%$ ), and MDAPE was $23.3 \%(18.8-27.8 \%)$. The divergence was $-20.3 \% \cdot \mathrm{hr}^{-1}$ $\left(-79.3-38.7 \% \cdot \mathrm{hr}^{-1}\right)$ and wobble was $12.9 \%$ ( 8.8 $17 \%$ ). The MDPE was positive for each sampling time, the largest deviation from predicted values occurring three minutes after an increase in the target concentration (Table II).
A mean change in arterial pressure of $-6.4 \%(95 \%$ confidence interval $-45.8-33 \%$ ) occurred and a mean variation in heart rate of $4.3 \%(-29.8-38.4 \%)$. Six patients suffered brief apneic episodes following induction of anesthesia but no further apneic episodes occurred. The mean end tidal $\mathrm{CO}_{2}$ concentration was $5.8 \%$ (range $3.6-8.5 \%$ ). The mean induction dose of propofol required was $2.21 \mathrm{mg} \cdot \mathrm{kg}^{-1}$ (range 1.51 $3.33 \mathrm{mg} \cdot \mathrm{kg}^{-1}$ ). The system allowed anesthesia to be performed using a conventional manual propofol infusion technique, the mean total requirements being 9.3 $\mathrm{mg} \cdot \mathrm{kg} \cdot \mathrm{hr}^{-1}$ with patients breathing an air/oxygen mixture. The mean dose of ketamine used was 0.94 $\mathrm{mg} \cdot \mathrm{kg} \cdot \mathrm{hr}^{-1}$ with individual patient requirements of 0.40 - $1.41 \mathrm{mg} \cdot \mathrm{kg} \cdot \mathrm{hr}^{-1}$. The depth of anesthesia appeared light as judged by pupil size and reaction but there were few instances of involuntary movement, none of which interfered with surgery, and no recall of awareness. The mean time from discontinuing the propofol infusion until eye opening was $13.3 \mathrm{~min}$ (range $4-25 \mathrm{~min}$ ) and until stating date of birth 22.3 min (range $7-43 \mathrm{~min}$ ). Regression analysis failed to reveal any relationship between the total doses of ketamine or propofol given or the duration of the procedure and these recovery times. No patient described unpleasant dreams or hallucinations, no major anesthetic complications occurred and all patients were well enough to be discharged from hospital at the planned time.

\section{Discussion}

The study had two purposes: to assess the accuracy of the computer programme for target controlled ketamine infusion and to test its suitability as an anesthetic technique in clinical use in conjunction with a propofol infusion.

The MDPE of the system was $18.9 \%$ demonstrating a tendency for the measured plasma ketamine concentrations to be higher than those predicted by the TCI system. The MDAPE, a measure of the precision of the system, was $23.3 \%$. The negative value obtained for divergence of the system, $-20.3 \%$, demonstrated a tendency for the difference between predicted and measured values to decrease with time, while the degree of intrapatient variability was given by a value for wobble of $12.9 \%$.

It has been suggested that a TCI system can be considered clinically acceptable if the MDPE is less than $20 \%$ and the MDAPE between 20 and $30 \%,{ }^{9}, 10$ both of which criteria were met by this system. There were, however, some sampling points where the positive bias was greater, notably three and five minutes after an increase in the target concentration (Table II). 
TABLE II Summary of predicted errors for each sampling point with range of errors for cach sampling point in brackets.

\begin{tabular}{lll}
\hline & $\begin{array}{l}\text { Median predicted } \\
\text { error (\%) }\end{array}$ & $\begin{array}{l}\text { Median absolute } \\
\text { predicted error (\%) }\end{array}$ \\
\hline 5 min after starting infusion & $28.5[-26.9-109.1]$ & $28.5[2.1-109.1]$ \\
Prior to start of procedure & $15.05[-17.5-46.1]$ & $16.95[2.5-46.1]$ \\
Prior to concentration increase & $21.05[2.3-67.4]$ & $21.05[2.3-67.4]$ \\
3 min after concentration increase & $59.5[13.7-119.4]$ & $59.5[-13.7-119.4]$ \\
5 min after concentration increase & $36.4[0.5-83.9]$ & $36.4[0.5-83.9]$ \\
Prior to concentration decrease & $23.5[-17.5-75]$ & $23.5[4.6-75]$ \\
On reaching new concentration & $9.3[-24.3-40.7]$ & $15.7[0.1-40.7]$ \\
5 min after reaching new concentration & $6.65[-24.5-60.7]$ & $14.85[0.2-60.7]$ \\
Prior to ending infusion & $25.9[-22.3-81.5]$ & $25.9[0.5-81.5]$ \\
5 min after ending infusion & $3.9[-33.7-51.7]$ & $15.5[0.9-51.7]$ \\
10 min after ending infusion & $10.6[-34.6-62.7]$ & $15.6[1.3-62.7]$ \\
Population & $18.9[95 \%$ confidence & $23.3[95 \%$ confidence \\
& interval 14-23.8] & interval 18.8-27.8] \\
\hline
\end{tabular}

Venous samples were used for concentration measurements since it was felt that an indwelling arterial cannula risked further morbidity which could not be justified in the patients chosen or surgical procedures performed. Since the venous concentration is lower than the arterial, the real bias at these points is likely to be even higher than that calculated. This might be of importance if the actual plasma ketamine concentrations achieved were high enough to produce undesirable effects. In fact, there were no clinical indications during anesthesia of any undesirable effect, nor were there any indications postoperatively that harm had resulted. This may not be surprising given that the plasma ketamine concentrations aimed for to provide analgesia meant that, even in the event of a considerably higher concentration being achieved, this still fell below the plasma concentrations achieved when ketamine is used as an induction agent. ${ }^{1}$ In addition it is not possible to measure ketamine concentrations at the actual effector site. After an increase in target concentration the effector site concentration is likely to be lower than the measured plasma concentration $^{11}$ and this would tend to reduce the bias at these points if this could be accurately measured.

Performance errors in the TCI system may be due to a basic error in the pharmacokinetic parameters used for the computer model but a major source of error is likely to be interindividual pharmacokinetic variability. Drug distribution, metabolism and excretion will be affected by the patients' age, weight and genetic predisposition as well as co-existing disease states and concurrent drug treatment. Such variability will always affect the efficiency of a TCI system but measures such as precision and bias are less important in clinical use than the ability, as with other methods for providing analgesia, to titrate the target drug con- centration against clinical effect.

The TCI ketamine system when used in conjunction with a manual propofol infusion proved to be an acceptable anaesthetic technique in clinical use. The overall propofol requirements of $9.3 \mathrm{mg} \cdot \mathrm{kg}^{-1} \cdot \mathrm{hr}^{-1}$ while breathing an air/oxygen mixture were comparable with those in previous studies where an air/nitrous oxide mixture was breathed ${ }^{12}$ and there was no prolongation in recovery time when compared to the combination of propofol and nitrous oxide ${ }^{12}$ or isoflurane and nitrous oxide. ${ }^{13}$ None of the patients in the study voiced any dissatisfaction with their experience when reviewed either in the recovery ward or $24 \mathrm{hr}$ post-operatively.

The mean decrease in blood pressure of $6.4 \%$ compares favourably with that observed in previous studies using propofol infusions with some studies demonstrating decreases in systolic and diastolic pressures of up to $47 \%,{ }^{14,15,16}$ and isoflurane anesthesia ${ }^{17}$ although the degree of variability $(95 \%$ confidence interval $-45.8-33 \%$ ) was greater than hoped. In only one patient was the fall in arterial pressure considered clinically unacceptable and this was quickly corrected by intravenous fluid administration.

We conclude that the system as used was clinically satisfactory, providing an adequate level of anesthesia for the procedures performed with a good ability to titrate analgesia rapidly to meet requirements and that such a system might provide an alternative to propofol/alfentanil TIVA systems where the sympathetic stimulating effects of ketamine could be considered beneficial.

\section{References}

1 Clements JA, Nimmo WS. Pharmacokinetics and analgesic effect of ketamine in man. Br J Anaesth 1981; 53: 27-30. 
2 Soliman $M G$, Brindle GF, Kuster G. Response to hypercapnia under ketamine anaesthesia. Can Anaesth Soc J 1975; 22: 486-94.

3 Idvall J, Ablgren I, Aronsen KF, Stenberg P. Ketamine infusions: pharmacokinetics and clinical effects. $\mathrm{Br} \mathrm{J}$ Anaesth 1979; 51: 1167-73.

4 Guit JBM, Koning HM, Coster ML, Niemeijer RPE, Mackie DP. Ketamine as analgesic for total intravenous anaesthesia with propofol. Anaesthesia 1991; 46: 24-7.

5 Mason DG, Swinhoe CF, Linkens DA, Reilly CS.

Development of a pharmacokinetic model-based infusion system for ketamine analgesia. Int J Clin Monit Comput 1996; 13: 139-42.

6 Weiber J, Gugler R, Hengstmann JH, Dengler HJ. Pharmacokinetics of ketamine in man. Anaesthetist 1975; 24: 260-3.

7 Chang T, Glazko AJ. A gas chromatographic assay for ketamine in human plasma. Anesthesiology 1972; 36: 401-4.

8 Varvel JR, Donoho DL, Shafer SL. Measuring the predictive performance of computer-controlled infusion pumps. J Pharmacokinet Biopharm 1992; 20: 63-94.

9 Schïttler J, Kloos S, Schwilden H, Stoeckel H. Total intravenous anaesthesia with propofol and alfentanil by computer assisted infusion. Anaesthesia 1988; 43(Suppl): 2-7.

10 Glass PSA, Shafer SL, Jacobs JR, Reves JG. Intravenous drug delivery systems. In: Miller RD (Ed.). Anesthesia, 4th ed. New York: Churchill Livingston Inc., 1994: 389-416.

11 Gepts E. Pharmacokinetic concepts for TCI aneasthesia. Anaesthesia 1998; 53(Suppl1): 4-12.

12 Turtle MJ, Cullen P, Prys-Roberts C, Coates D, Monk $C R$, Faroqui $M H$. Dose requirements of propofol by infusion during nitrous oxide anaesthesia in man. II: Patients premedicated with lorazepam. $\mathrm{Br}$ J Anaesth 1987; 59: 283-7.

13 Campbell C, Nabrwold ML, Miller DD. Clinical comparison of sevoflurane and isoflurane when administered with nitrous oxide for surgical procedures of intermediate duration. Can J Anaesth 1995; 42: 884-90.

14 Roberts FL, Dixon J, Lewis GTR, Tackley RM, PrysRoberts $C$. Induction and maintenance of propofol anaesthesia. A manual infusion scheme. Anaesthesia 1988; 43(Suppl): 14-7.

15 Monk CR, Coates DP, Prys-Roberts C, Turtle MJ, Spelina $K$. Haemodynamic effects of a prolonged infusion of propofol as a supplement to nitrous oxide anaesthesia. Studies in association with peripheral arterial surgery. Br J Anaesth 1987; 59: 954-60.

16 Claeys $M A$, Gepts E, Camu F. Haemodynamic changes during anaesthesia induced and maintained with propofol. Br J Anaesth 1988; 60: 3-9.
17 Oikkonen $M$. Isoflurane and enflurane in long anaesthesias for plastic microsurgery. Acta Anaesthesiol Scand $1984 ; 28: 412-8$. 